\title{
Major care gaps in asthma, sleep and chronic obstructive pulmonary disease: A road map for knowledge translation
}

\author{
Louis-Philippe Boulet MD FRCPC ${ }^{1}$, Jean Bourbeau MD FRCPC ${ }^{2,3}$, Robert Skomro MD FRCPC ${ }^{4}$, Samir Gupta MD FRCPC 5
}

L-P Boulet, J Bourbeau, R Skomro, S Gupta. Major care gaps in asthma, sleep and chronic obstructive pulmonary disease: A road map for knowledge translation. Can Respir J 2013;20(4):265-269.

Large gaps between best evidence-based care and actual clinical practice exist in respiratory medicine, and carry a significant health burden. The authors reviewed two key care gaps in each of asthma, chronic obstructive pulmonary disease and obstructive sleep apnea. Using the 'Knowledge-toAction Framework', the nature of each gap, its magnitude, the barriers that cause and perpetuate it, and past and future strategies that might address the problem were considered. In asthma: disease control is ascertained inadequately, leading to a prevalence of poor asthma control of approximately $50 \%$; and asthma action plans, a key component of asthma management, are provided by only $22 \%$ of physicians. In obstructive sleep apnea: disease is under-recognized, with sleep histories ascertained in only $10 \%$ of patients; and Canadian polysomnography wait times remain longer than recommended, leading to unnecessary morbidity and societal cost. In chronic obstructive pulmonary disease: a large proportion of patients seen in primary care remain undiagnosed, mainly due to underuse of spirometry; and $<10 \%$ of patients are referred for pulmonary rehabilitation, despite strong evidence demonstrating its cost effectiveness. Given the prevalence of these chronic conditions and the size and nature of these gaps, the latter exact an important toll on patients, the health care system and society. In turn, complex barriers at the patient, provider and health care system levels contribute to each gap. There have been few previous attempts to bridge these gaps. Innovative and multifaceted implementation approaches are needed and have the potential to make a large impact on Canadian respiratory health.

Key Words: Asthma; Chronic obstructive lung disease; Guidelines; Implementation; Knowledge translation; Obstructive sleep apnea

$\mathrm{n}$ respiratory medicine, as in other disciplines, the vast and rapid growth of medical knowledge has largely been met with a disappointingly low uptake to realize improved patient outcomes. The existence of gaps between established scientific evidence and actual care gives rise to the need for dedicated knowledge translation (KT) activities in respirology. In the present narrative review, we focus on two key care gaps in each of three highly prevalent respiratory conditions in Canada: asthma, obstructive sleep apnea (OSA) and chronic obstructive pulmonary disease (COPD). An expert in each field first identified care gaps in each disease (Table 1) and then chose two gaps for discussion (given space limitations), based on the strength of the evidence supporting the practice in question, the importance of the outcomes associated with the practice, the magnitude and corresponding Canadian public health burden of the care gap, the existence of evidence regarding barriers and facilitators to the practice in question, and the feasibility of overcoming the gap. Our goal was to expose care gaps related to practices considered to be essential in these diseases and, thereby, provide a set of high-yield potential future targets for clinicians, KT researchers and policy makers considering implementation activities. The 'Knowledge-to-Action Framework' (1) provides a Des lacunes importantes dans les soins de l'asthme, du
sommeil et de la maladie pulmonaire obstructive chronique : feuille de route pour la transmission du savoir

Il existe des lacunes importantes entre les meilleurs soins fondés sur des données probantes et la véritable pratique clinique en médecine respiratoire, qui s'associent à un fardeau marqué pour la santé. Les auteurs ont analysé deux grandes lacunes des soins dans les secteurs de l'asthme, de la maladie pulmonaire obstructive chronique et de l'apnée obstructive du sommeil. À l'aide du « processus des connaissances à la pratique », ils ont évalué la nature de chaque lacune, sa magnitude, les obstacles qui l'entraînent et la perpétuent et les stratégies passées et futures qui pourraient régler le problème. Dans le cas de l'asthme, le contrôle de la maladie est mal établi, ce qui entraîne une prévalence d'environ 50 \% des cas de mauvais contrôle de l'asthme, et environ 22 \% des médecins fournissent un plan d'action sur l'asthme, qui constitue pourtant un élément clé de la prise en charge de l'asthme. Pour ce qui est de l'apnée obstructive du sommeil, la maladie est sousreconnue, les antécédents de sommeil n'étant vérifiés que chez $10 \%$ des patients. Les temps d'attente canadiens en polysomnographie demeurent plus longs que les recommandations, ce qui s'associe à une morbidité inutile et à des coûts pour la société. Enfin, en matière de maladie pulmonaire obstructive chronique, une forte proportion de patients vus en première ligne demeure non diagnostiquée, en grande partie à cause de la sous-utilisation de la spirométrie. Moins de $10 \%$ des patients sont aiguillés en réadaptation pulmonaire, malgré les données probantes solides en appuyant le rapport coût-efficacité. Étant donné la prévalence de ces maladies chroniques ainsi que l'importance et la nature de ces lacunes, celles-ci ont des conséquences très néfastes sur les patients, le système de santé et la société. De même, les obstacles complexes auxquels se heurtent les patients, les dispensateurs et le système de santé contribuent à chaque lacune. Peu de tentatives ont été entreprises pour corriger ces lacunes. Des démarches de mise en œuvre novatrices et polyvalentes s'imposent et pourraient avoir des effets considérables sur la santé respiratoire au Canada.

systematic approach to addressing key care gaps. Accordingly, we followed the steps in this framework in elaborating on barriers, previous implementation efforts and possible future strategies for each gap discussed herein.

\section{ASTHMA}

In Canada, asthma affects approximately $10 \%$ of the population, and accounts for more than 150,000 emergency department visits, 60,000 hospital stays and $\$ 2$ billion in annual costs (2). The first Canadian Asthma Consensus Guideline (CACG) was published in 1990, and regular updates have followed in addition to other international guidelines (3). Early efforts devoted to dissemination and implementation of these guidelines in many countries, including Canada, have met with variable results $(4,5)$.

Care gap 1: Inadequate assessment of asthma control for treatment adjustment

The overarching goal of asthma treatment is to achieve good asthma control. Evidence-based criteria for 'good control' have been defined to minimize symptoms, maximize patient quality of life and avoid significant complications. These have been articulated explicitly in the

\footnotetext{
${ }^{1}$ Institut universitaire de cardiologie et de pneumologie de Québec, Université Laval, Québec; ${ }^{2}$ Respiratory Epidemiology and Clinical Research Unit, Montreal Chest Institute, McGill University Health Centre; ${ }^{3}$ Department of Epidemiology, Biostatistics and Occupational Health, McGill University, Montréal, Québec; ${ }^{4}$ University of Saskatchewan, Saskatoon, Saskatchewan; ${ }^{5}$ The Keenan Research Centre in the Li Ka Shing Knowledge Institute of St Michael's Hospital, Department of Medicine, University of Toronto, Toronto, Ontario

Correspondence: Dr Samir Gupta, Keenan Research Centre in the Li Ka Shing Knowledge Institute of St Michael's Hospital Suite 6044, Bond Wing, 30 Bond Street, Toronto, Ontario M5B 1W8. Telephone 416-864-6060 ext 2252, fax 416-864-5649, e-mail guptas@smh.ca
} 
TABLE 1

Key potential care gaps in asthma, obstructive sleep apnea (OSA) and chronic obstructive pulmonary disease (COPD)

Asthma OSA

Health care practitioner- or system-driven care gaps

Inadequate assessment of asthma control

Under-recognition of OSA

Failure to provide a written asthma action plan

Underuse of spirometry, resulting in overdiagnosis

Failure to refer to a specialist when required

Failure to provide asthma education

Failure to address smoking cessation

Delayed diagnostic testing for OSA (in adults and children)

Underreferral to sleep specialists for OSA management

Lack of validated action plans for OSA treatment

Undertreatment of OSA

Inconsistent follow-up in OSA
COPD

Underuse of spirometry, resulting in underdiagnosis, inappropriate diagnosis

Low referral rates for pulmonary rehabilitation

Lack of access to a case manager and a self-management program

Failure to offer influenza vaccination

Inappropriate therapeutic initiation and escalation

Failure to address smoking cessation

Poor adherence to treatment

Poor adherence to pulmonary rehabilitation and exercise maintenance

Poor ability to recognize the signs and symptoms of an exacerbation

Non-use/misunderstanding of the asthma action plan

CPAP Continuous positive airway pressure

CACGs and other international guidelines and include: limited dayand night-time symptom and rescue bronchodilator use frequency; freedom from activity limitation, work or school absenteeism, and anything more than mild, infrequent exacerbations; and optimal pulmonary function (6). Given that the presence of any of these criteria is what defines the need for therapeutic initiation or escalation, guidelines recommend control assessment at every clinical visit. It has been shown that adequate control can be achieved in a majority of patients if therapeutic changes are made in response to suboptimal control (3).

Unfortunately, clinical assessment of asthma control criteria is seldomly performed. More than $50 \%$ of patients with asthma are poorly controlled, with frequent daytime symptoms, asthma-related nocturnal arousals, missed school or work, recurrent need for urgent medical care and an increased risk of death (7). Evidence suggests that although other factors, such as patient adherence, contribute to suboptimal control, failure to assess asthma control is a major contributor, and is attributable to lack of familiarity with control criteria among physicians. In one study, Canadian primary care physicians could only identify a mean of 2.2 of eight CACG control criteria (8). In another Canadian study, primary care physicians labelled $31 \%$ of their inadequately controlled patients as "well controlled" when presented with patient-reported symptoms (9). In addition to a lack of knowledge about criteria themselves, insufficient time for control evaluation and/or simply forgetting to assess control may constitute other barriers. This problem is compounded by low patient expectations for disease control, whereby patients fail to alert physicians of their poor control.

In one of the few studies that attempted to bridge this gap, Renzi et al (8) provided physicians with a self-inking paper stamp that could be used to stamp control criteria with adjacent checkboxes on successive asthma patient charts. Use of the stamp significantly increased knowledge of control criteria among physicians, and patients of physicians who received the stamp had significantly fewer emergency room visits and a trend toward fewer hospitalizations compared with patients of physicians who did not. This simple intervention both addressed the knowledge barrier identified above and provided physicians with a reminder to assess control. Interestingly, a concurrent continuing medical education intervention appeared to have little or no incremental effect on knowledge. Other potential strategies that could address these barriers and should be assessed in future studies include: direct patient education about appropriate control (whereby patients could prompt clinicians to address control); performance incentives for clinicians to assess control; use of dedicated asthma educators for control assessment; and electronic practice-based tools such as reminders and decision support embedded in the electronic medical record (EMR) system.

Care gap 2: Failure to provide a written asthma action plan Asthma control can change with time, particularly when a patient is exposed to various triggers such as allergens and respiratory infections. To minimize morbidity from these transient losses of control, individualized written asthma action plans (AAPs) provide education and guidelines for self-management of worsening asthma symptoms, including when and how patients should modify their medications and access the medical system. AAPs have been studied extensively in randomized controlled trials, and a Cochrane review (10) demonstrated that, in conjunction with education and regular clinical review, they significantly reduce health care utilization, absenteeism and symptoms, and improve quality of life. Accordingly, CACGs and other international guidelines recommend that all patients receive a written AAP (Level I evidence) (6).

Unfortunately, the rate of AAP provision by clinicians to their patients is uniformly low across jurisdictions, practice types and patient age groups. In an Australian study involving 443 children with asthma two to 14 years of age, only $29 \%$ owned a written AAP (11). In Canada, $22 \%$ of physicians report providing a written AAP, while only $11 \%$ of patients with asthma report receiving one (9).

Qualitative studies evaluating barriers to AAP delivery in primary care suggest that a lack of necessary time to produce and explain the AAP is the most important factor. Many physicians also lack experience and confidence in completing an AAP, and it has been previously shown that a significant number of primary care physicians are unable to prepare an adequate AAP. Physicians may also have a low awareness of the importance of AAPs, given that even when asthma educators were available to produce AAPs, referrals to educators were made in no more than one-third of patients (12).

Few previous studies have attempted to improve AAP delivery by physicians, and simple strategies, such as physician education and reminders, have been unsuccessful, likely because they failed to address the main barrier of time constraints. Possible approaches that have shown promise include physician incentive programs coupled with help from asthma educators, although these are also costly to set up and maintain. Future research should measure the cost effectiveness of such strategies, and explore novel strategies such as tools that could improve the efficiency of creating AAPs in real-world practice (13). 


\section{OSA}

OSA is one of the most common chronic conditions in Canada, with recent evidence suggesting a prevalence of up to $20 \%$ among Canadian adults (14). Untreated OSA presents a considerable socioeconomic burden, including deleterious effects on patient health outcomes, as well increased rates of health care utilization, medication use, motor vehicle accidents and income loss. The Canadian Thoracic Society (CTS) first published evidence-based OSA guidelines in 2006, with a subsequent update in 2011 (15), and British, Spanish and American guidelines have also been published recently. While CTS dissemination efforts have included presentations to various health care professional groups, distribution of printed educational material ('Slim Jims'), and free online availability on CTS and publisher websites, active implementation is currently being planned and has not yet been evaluated.

\section{Care gap 1: Under-recognition of OSA}

OSA has major health consequences for the patient, including impaired quality of life, daytime sleepiness, impairment of cognitive function, mood and personality changes, arterial hypertension and cardiovascular morbidity. As noted, societal impacts include increased health care utilization and motor vehicle accidents (15). Treatment with continuous positive airway pressure has been clearly demonstrated to improve most of these outcomes in high-quality primary studies and a systematic review (16), and costs only $\$ 3,354$ per qualityadjusted life year, which compares favourably with established chronic disease therapies (17).

Accordingly, early identification for objective diagnostic testing of patients at risk for OSA would have significant health benefits and has been recommended explicitly in CTS guidelines (15).

Early identification requires clinical screening for the presence of OSA in patients with high-risk features. Unfortunately, sleep histories are taken in only $10 \%$ of patients seen in primary care (18). Accordingly, only $24 \%$ of patients' sleep concerns were identified in primary care visits, and those identified were rarely investigated (19). In another primary care study, $33 \%$ of patients were at high risk for OSA, but only $9 \%$ of charts had documentation of OSA and only $2 \%$ of patients were referred to a sleep clinic (20). This care gap exists despite the fact that those at high risk for OSA are far more likely to report adverse health outcomes.

There are numerous reasons for failure to identify patients at risk for OSA. Barriers identified by primary care physicians include both a lack of confidence in managing patients with sleep complaints (self-efficacy) and deficits in sleep knowledge (21). These barriers are attributable, in part, to the fact that exposure to sleep medicine in undergraduate and postgraduate medical curricula is limited (22). Furthermore, prospective studies suggest that patients rarely voluntarily disclose sleep symptoms (23).

Previous studies have attempted to improve the recognition of OSA in primary care. For example, a practice-based tool providing clinicians with standardized 'review of systems' forms or validated sleep questionnaires improved recognition of OSA and showed the potential to increase access to therapy (20). Although efficacy data are lacking, two provinces (Saskatchewan and Manitoba) have also implemented OSA care pathways with public funding for an 'identify and diagnose' approach, featuring screening questionnaires and limited channel diagnostic recordings.

Future studies should assess the feasibility, efficacy and cost effectiveness of OSA care pathways, questionnaires and forms in primary care, including prompt-driven systems functioning through EMRs. Another important approach will be to increase emphasis on and training in sleep history-taking skills in medical school and family medicine residency curricula. Finally, patient-mediated strategies may be attempted by increasing public awareness, targeting high-risk patients, and asking them to prompt their physicians to consider the diagnosis.
Care gap 2: Delayed diagnostic testing for OSA

Given the morbidities of OSA and the advantages of therapy described above, delays between clinical suspicion and diagnosis carry important potential consequences for both patients and the health care system. In one study, patients randomly assigned to expedited testing had significantly better quality of life than those receiving standard care with diagnostic delays. On a system level, once a diagnosis of OSA was made and treatment initiated, care expenses decreased by almost $50 \%$ (24). Hospital length of stays in patients before compared with after OSA diagnosis were 1.27 and 0.53 days per patient per year, respectively (25). Accordingly, current CTS guidelines recommend that all adult patients suspected of having OSA be diagnosed objectively within six months (GRADE: 2C), and those with significant comorbidities and/or at occupational risk, within four weeks.

Unfortunately, current wait times for OSA diagnosis in Canada do not consistently fit within these acceptable limits, which represents a major care gap. Canadian wait times for polysomnography (PSG), the diagnostic test of choice, were estimated to average between eight and 36 months depending on the region of the country (26). Compared with other nations, total wait time for diagnosis and treatment was longer in Canada than in the United States, Australia and Belgium, but shorter than in the United Kingdom (26). Even in Ontario, which has the highest number of PSG beds per capita in the country, patients waited an overall mean of 4.9 months for PSG, and wait times were highly variable across the province (27).

The most important barrier to timely diagnosis in patients with suspected OSA is the availability of testing facilities. In any particular geographical area, availability of a larger number of sleep laboratories was significantly associated with shorter wait times, with each additional regional laboratory decreasing overall wait times by $20 \%$ $(15,27)$. Currently, Canada has only 131 adult and eight pediatric sleep diagnostic facilities providing in-laboratory PSG, and many of these are concentrated in urban areas, accounting for the reported regional disparities in PSG access (15). Likely contributors to our inadequate PSG capacity include both a rapid growth in OSA prevalence and health care resource limitations. As obesity rates in both adult and pediatric populations continue to increase, it is expected that wait times for OSA testing will only worsen unless solutions are found.

Strategies to overcome this barrier will require creativity and should be a focus of future research. One approach may be to increase the use of limited channel and portable monitoring, which is less costly and more widely available than full PSG, and can confirm the diagnosis of OSA in patients with a moderate to high pretest probability of disease (15). This approach, along with expert consultation through Telehealth, may be particularly effective in jurisdictions with limited specialist availability and PSG capacity.

\section{COPD}

COPD is a growing cause of morbidity and mortality. In Canada, the prevalence of Global Initiative for Chronic Obstructive Lung Disease (GOLD) grade 2 or higher COPD in the population $\geq 40$ years of age is $8.6 \%$ in men and $7.2 \%$ in women, affecting more than 1.2 million people (28).

Canadian COPD consensus guidelines were first published in 2003 and updated in 2007 (29), along with special formatting in an effort to make them easy for family physicians to use. However, significant care gaps remain.

\section{Care gap 1: Underuse of spirometry for COPD diagnosis}

A large proportion of patients with COPD seen in primary care remain undiagnosed, including $50 \%$ of patients with severe COPD (GOLD grade $\geq 3$ ) (30). In a Canadian primary care study, 20\% of patients $\geq 40$ years of age with a smoking history had COPD, but only one-third were diagnosed (30). The consequences of this underdiagnosis include untreated symptoms, and preventable recurrent exacerbations, emergency department visits and hospital admissions. 
The reason for underdiagnosis is a failure to perform or order diagnostic spirometry. Incorporation of spirometry results in primary care has an important and appropriate effect on COPD-related care decisions. In one study, use of spirometry was followed by changes in management in $48 \%$ of the patients, including both nonpharmacological and pharmacological treatments, with $85 \%$ of changes being guideline concordant (31). Accordingly, use of spirometry for COPD diagnosis (in patients with any respiratory symptoms) has been recommended in international and Canadian COPD guidelines (29). Furthermore, most international guidelines suggest that it would be better if spirometry were performed in the office setting rather than in specialized referral laboratories, and studies have shown that this can be accomplished accurately and reliably with currently available technologies (32).

Despite these strong data, only $56 \%$ of Canadian patients with a clinical diagnosis of COPD in primary care have undergone an objective spirometric diagnosis (33). This suggests that underuse of spirometry may also result in inappropriate diagnosis. Reported reasons for this underuse include limited access to spirometry (25\%), not recognizing spirometry as a diagnostic tool $(65 \%)$ and lack of comfort with the interpretation of the spirometry results (81\%) (34). A Canadian study measured factors affecting the implementability of spirometry in 12 real-life primary care environments and found access to a trained health care professional to be the most powerful facilitator to spirometry use (unpublished data). A false physician perception that a symptom-based diagnosis of COPD is reliable (despite evidence to the contrary) may be an important barrier (33).

Implementation efforts to bridge this important care gap have been limited. In one study, 'opportunistic' spirometry testing by nurses visiting medical practices substantially increased the use of spirometry compared with usual care (35). However, this is a resource-intensive intervention and would require cost-effectiveness evaluation. Ultimately, solutions to bridge this care gap will likely require a multifactorial approach, including a system-level change whereby allied health support can be made widely available for spirometry performance in primary care (likely by leveraging a similar need for spirometry in asthma); practice-based tools for spirometry interpretation (such as EMR-based decision support tools that assist in interpretation and clinical decision-making based on spirometry results); and interactive continuing medical educational activities that educate primary care physicians regarding the pitfalls and deleterious consequences of a symptom-based COPD diagnosis.

\section{Care gap 2: Low referral rates for pulmonary rehabilitation}

COPD of any severity can be associated with reduced physical capacity and activity and, correspondingly, a reduced quality of life. Furthermore, COPD exacerbations consume considerable heath resources, accounting for $\$ 1.5$ billion in annual health care costs (36).

Pulmonary rehabilitation (PR) includes a program of exercises that helps patients build their physical fitness, education in areas such as breathing techniques and training in various strategies to cope with the effects of COPD. Several studies have shown that PR has a significant impact on the important COPD morbidities mentioned above, including reduction in dyspnea and fatigue, increase in exercise capacity, improvement in emotional function along with an enhanced sense of control over the condition and reduction in health care utilization (29). These improvements are moderately large and clinically significant (29). Accordingly, Canadian guidelines recommend PR for all patients with persistent symptoms despite optimal pharmacotherapy (Level of evidence: 1A), and for all those with moderate, severe and very severe disease (GRADE: 1C) (29).

Unfortunately, in Canada, only a minority of COPD patients $(<10 \%)$ are referred for PR (33). One important barrier in many jurisdictions appears to be accessibility and availability of PR programs (37). The CTS guidelines have indicated that increased access to PR programs across the country is urgently needed (Level of evidence: 2A) (29). Qualitative research revealed that patient-level barriers include a lack of knowledge of the benefits of PR along with concerns regarding travel distances to program locations, while physician-level barriers include a lack of knowledge of the benefits of PR (38). This latter factor was attributed to a medical culture ascribing low value to nonpharmacological treatments and inadequate training in chronic disease management.

Again, efforts to address these important barriers through novel implementations have been few and far between. A Canadian trial has challenged the need for dedicated institutional programs as the only setting to deliver PR by designing and demonstrating the effectiveness and safety of a self-monitored, home-based PR program (39). Such a model could address system-level barriers related to PR access, but also patient-level barriers relating to travel costs and time. In another strategy, a COPD discharge care bundle appropriately increased PR referrals at the time of hospital discharge (40). Combinations of strategies such as these, which address system-, physician- and patient-level barriers, will be required to overcome this complex care gap. Furthermore, engagement of health care decision makers will be crucial for systemlevel changes to be enacted. Given that PR has been shown to be cost effective through reductions in health care utilization costs, a strong argument for system-level investments can be made, even with current resource limitations.

\section{CONCLUSION}

Much important new knowledge has been generated in the field of respiratory medicine in the past decade alone; however, patients have yet to benefit fully from these advancements. Accordingly, there is an urgent need for KT activities to 'catch up' to these ongoing knowledgecreation activities. Care gaps described in the present article were based on single-expert opinion. Future studies should use both a systematic literature review to identify all possible relevant care gaps and a Delphi process among several content experts to prioritize these. Regardless, there is clearly a need for KT even in the most common respiratory diseases. As institutional and governmental priorities shift toward implementation projects, concurrent objective measurements of their effects will be required. Here, implementers and KT researchers will have opportunities to leverage existing knowledge for large impacts on health outcomes.

AUTHOR CONTRIBUTIONS: All authors shared in the conception, authorship and review of the manuscript. LPB authored the asthma section, RS authored the OSA section, and JB authored the COPD section.

DISCLOSURES: SG, RS, JB and LPB have no financial disclosures or conflicts of interest to declare.

\section{REFERENCES}

1. Graham ID, Logan J, Harrison MB, et al. Lost in knowledge translation: Time for a map? J Contin Educ Health Prof 2006;26:13-24.

2. Canadian Institute for Health Information, Canadian Lung Association, Health Canada, Statistics Canada. Respiratory Disease in Canada, 1st edn. Ottawa: Health Canada, 2001:1-102.

3. Boulet L. Asthma guidelines and outcomes. In: Adkinson MF Jr, Busse WW, Bochner BS, Holgate ST, Simons FER, eds. Middleton's Allergy Principles and Practice, 6th edn. Philadelphia: Mosby, 2003:1283-301.

4. Chapman KR, Ernst P, Grenville A, et al. Control of asthma in Canada: Failure to achieve guideline targets. Can Respir J 2001;8(Suppl A):35A-40A.

5. Partridge MR, Harrison BD, Rudolph M, et al. The British Asthma Guidelines - their production, dissemination and implementation. British Asthma Guidelines Co-ordinating Committee. Respir Med 1998;92:1046-52.

6. Lougheed MD, Lemiere C, Ducharme FM, et al. Canadian Thoracic Society 2012 guideline update: Diagnosis and management of asthma in preschoolers, children and adults. Can Respir J 2012;19:127-64. 
7. FitzGerald JM, Boulet LP, McIvor RA, et al. Asthma control in Canada remains suboptimal: The Reality of Asthma Control (TRAC) study. Can Respir J 2006;13:253-9.

8. Renzi PM, Ghezzo H, Goulet S, et al. Paper stamp checklist tool enhances asthma guidelines knowledge and implementation by primary care physicians. Can Respir J 2006;13:193-7. (Erratum in 2006;13[5]:279).

9. Chapman KR, Boulet LP, Rea RM, et al. Suboptimal asthma control: Prevalence, detection and consequences in general practice. Eur Respir J 2008;31:320-5.

10. Gibson PG, Coughlan J, Wilson AJ, et al. Self-management education and regular practitioner review for adults with asthma. Cochrane Database Syst Rev 2000;(2), update in 2003;(1):CD001117.

11. Sulaiman ND, Barton CA, Abramson MJ, et al. Factors associated with ownership and use of written asthma action plans in NorthWest Melbourne. Primary Care Respir J 2004;13:211-7.

12. Boulet L-P, Devlin H, O'Donnell DE. The Physicians' Practice Assessment Questionnaire on asthma and COPD. Respir Med 2011;105:8-14.

13. Boulet L-P, Becker A, Bowie D, et al. Implementing practice guidelines: A workshop on guidelines dissemination and implementation with a focus on asthma and COPD. Can Respir J 2006;13(Suppl A):5-47.

14. Public Health Agency of Canada. What is the impact of sleep apnea on Canadians? Facts from the 2009 Canadian Community Health Survey Public Health Agency of Canada. <www.phac-aspc. gc.ca/cd-mc/sleepapnea-apneesommeil/ff-rr-2009-eng.php> (Accessed February 3, 2013).

15. Fleetham J, Ayas N, Bradley D, et al. Canadian Thoracic Society 2011 guideline update: Diagnosis and treatment of sleep disordered breathing. Can Respir J 2011;18:25-47.

16. Giles TL, Lasserson TJ, Smith BH, White J, Wright J, Cates CJ. Continous positive airway pressure for obstructive sleep apnoea in adults. Cochrane Datbase Syst Rev 2006;19(3):CD001106.

17. Ayas NT, FitzGerald JM, Fleetham JA, et al. Cost-effectiveness of continuous positive airway pressure therapy for moderate to severe obstructive sleep apnea/hypopnea. Arch Intern Med 2006;166:977-84.

18. Reuveni H, Tarasiuk A, Wainstock T, et al. Awareness level of obstructive sleep apnea syndrome during routine unstructured interviews of a standardized patient by primary care physicians. Sleep 2004;27:1518-25.

19. Grover M, Mookadam M, Armas D, et al. Identifying patients at risk for obstructive sleep apnea in a primary care practice. J Am Board Fam Med 2011;24:152-60.

20. Senthilvel E, Auckley D, Dasarathy J. Evaluation of sleep disorders in the primary care setting: History taking compared to questionnaires. J Clin Sleep Med 2011;7:41-8.

21. Hayes SM, Murray S, Castriotta RJ, et al. (Mis) perceptions and interactions of sleep specialists and generalists: Obstacles to referrals to sleep specialists and the multidisciplinary team management of sleep disorders. J Clin Sleep Med 2012;8:633-42.

22. Strohl KP. Sleep medicine training across the spectrum. Chest 2011;139:1221-31.

23. Mold JW, Quattlebaum C, Schinnerer E, et al. Identification by primary care clinicians of patients with obstructive sleep apnea:
A practice-based research network (PBRN) study. J Am Board Fam Med 2011;24:138-45.

24. Bahammam A, Delaive K, Ronald J, et al. Health care utilization in males with obstructive sleep apnea syndrome two years after diagnosis and treatment. Sleep 1999;22:740-7.

25. Peker Y, Hedner J, Johansson A, et al. Reduced hospitalization with cardiovascular and pulmonary disease in obstructive sleep apnea patients on nasal CPAP treatment. Sleep 1997;20:645-53.

26. Flemons WW, Douglas NJ, Kuna ST, et al. Access to diagnosis and treatment of patients with suspected sleep apnea. Am J Respir Crit Care Med 2004;169:668-72.

27. Rotenberg B, George C, Sullivan K, et al. Wait times for sleep apnea care in Ontario: A multidisciplinary assessment. Can Respir J 2010;17:170-4.

28. Tan WC, Bourbeau J, FitzGerald JM, et al. Can age and sex explain the variation in COPD rates across large urban cities? A population study in Canada. Int J Tuberc Lung Dis 2011;15:1691-8.

29. O'Donnell DE, Aaron S, Bourbeau J, et al. Canadian Thoracic Society recommendations for management of chronic obstructive pulmonary disease - 2007 update. Can Respir J 2007;14(Suppl B):5B-32B.

30. Hill K, Goldstein RS, Guyatt GH, et al. Prevalence and underdiagnosis of chronic obstructive pulmonary disease among patients at risk in primary care. CMAJ 2010;182:673-8.

31. Yawn BP, Enright PL, Lemanske RF, Jr, et al. Spirometry can be done in family physicians' offices and alters clinical decisions in management of asthma and COPD. Chest 2007;132:1162-8.

32. Ferguson GT, Enright PL, Buist AS, et al. Office spirometry for lung health assessment in adults: A consensus statement from the National Lung Health Education Program. Chest 2000;117:1146-61.

33. Bourbeau J, Sebaldt RJ, Day A, et al. Practice patterns in the management of chronic obstructive pulmonary disease in primary practice: The CAGE study. Can Respir J 2008;15:13-9.

34. Canadian Lung Association. Chronic Obstructive Pulmonary Disease (COPD): A National Report Card, 2005. <www.lung.ca/_resources/2005.copd_reportcard.pdf> (Accessed February 15, 2013).

35. Walters JA, Hansen EC, Johns DP, et al. A mixed methods study to compare models of spirometry delivery in primary care for patients at risk of COPD. Thorax 2008;63:408-14.

36. Benady S. The Human and Economic Burden of COPD: A Leading Cause of Hospital Admission in Canada. Ottawa: Canadian Thoracic Society, 2010.

37. Brooks D, Sottana R, Bell B, et al. Characterization of pulmonary rehabilitation programs in Canada in 2005. Can Respir J 2007;14:87-92.

38. Surpas P. [Why is pulmonary rehabilitation so underused? How can this situation be improved?]. Rev Respir 2010;27:5-7.

39. Maltais F, Bourbeau J, Shapiro S, et al. Effects of home-based pulmonary rehabilitation in patients with chronic obstructive pulmonary disease: A randomized trial. Summary for patients in Ann Intern Med 2008;149:156; Ann Intern Med 2008;149:869-78.

40. Hopkinson NS, Englebretsen C, Cooley N, et al. Designing and implementing a COPD discharge care bundle. Thorax 2012;67:90-2. 


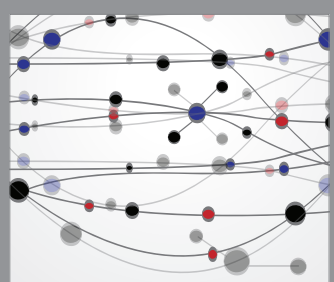

The Scientific World Journal
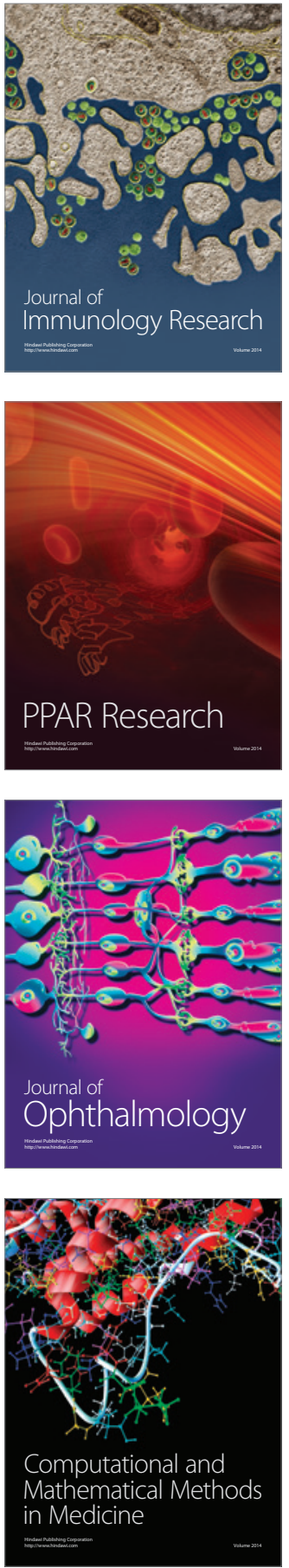

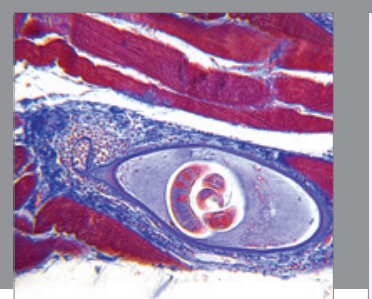

Gastroenterology Research and Practice

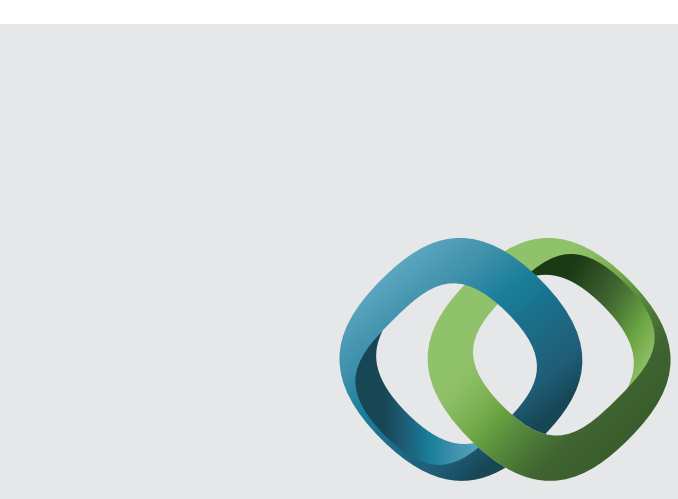

\section{Hindawi}

Submit your manuscripts at

http://www.hindawi.com
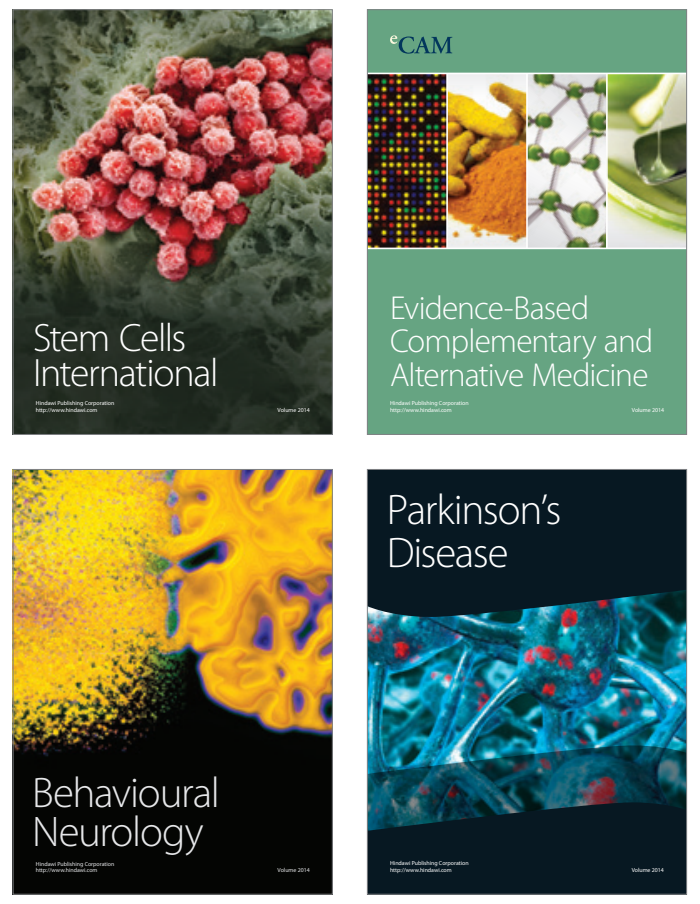
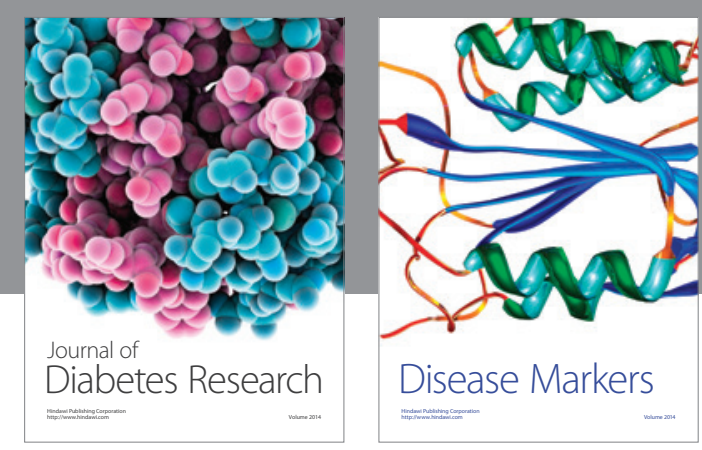

Disease Markers
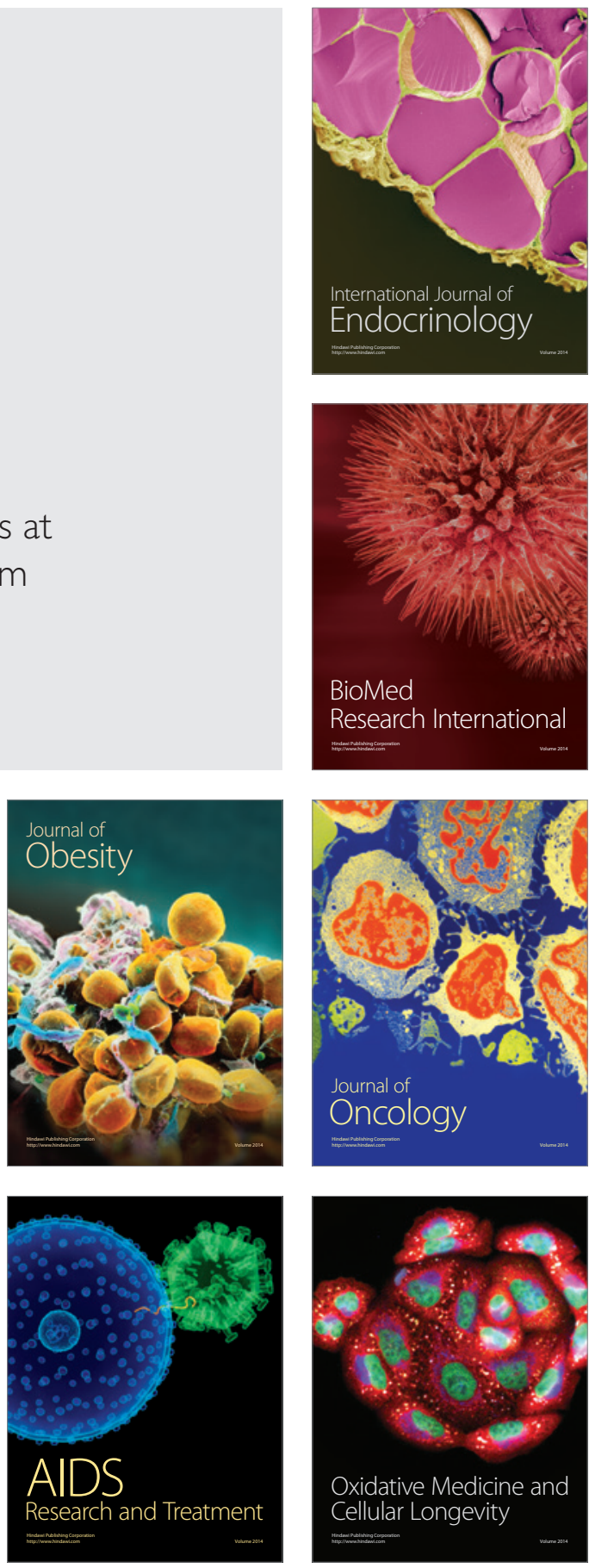